\title{
TOWARD A WIDER AUDIENCE, SYSTEMATIC APPROACH OF REINTERPRETATION AND REPRESENTATION OF THE EAST MAIN HALL OF FOGUANG TEMPLE BASED ON DIGITAL DOCUMENTATION AND 3D VISUALIZATION TECHNIQUES
}

\author{
Z.Y.Li ${ }^{1}$, Y.Gu ${ }^{1}$, R.Zhang ${ }^{1}$ \\ ${ }^{1}$ Beijing Guowenyan Cultural Heritage Conservation Center Co.,Ltd. Beijing, China-1269539675@qq.com; \\ guyunpei@conservision.com; 27898098@qq.com
}

KEY WORDS: Interpretation, Representation, Storytelling, Digital Cultural Heritage, Foguang Temple

\begin{abstract}
:
Rebuilt in $857 \mathrm{AD}$, the East Main Hall of Foguang Temple is the highest ranking wooden architecture to survive from the Tang Dynasty, and is regarded as a rare cultural and architectural gem of China and of the world at large1. Since its rediscovery in 1937, extensive research on the East Main Hall of Foguang Temple has been conducted, mostly about its high values and methods applicable to its conservation and management, while less attention is given to its interpretation and representation, especially to the public audiences.

Based on continued digital documentation and study of the East Main Hall of Foguang Temple by Tsinghua Univeristy and Beijing Guowenyan Cultural Heritage Conservation Center over the past 16 years, this paper is a comprehensive overview of the ongoing systematic attempt to leverage digital documentation and acquired research results as content and tool for heritage interpretation and presentation. The works involved include translation of digital survey and documentation of the wooden structure, colored statues and murals of Foguang Temple as content in three approaches: the first approach is the development of an on-site digital display system for Foguang Temple; the second approach involves the planning and designing of a large-scale interactive museum exhibition; the third approach, which wraps up the whole system into a public-centered storytelling experience, involves an ongoing animation series on air at multiple social media platforms that tells unknown stories about Foguang Temple. All three approaches are intended at developing emotional connections between the public and the cultural heritage through reinterpretation and representation, with the aim of making heritage dissemination more dialogical and sustainable by bringing history to life.
\end{abstract}

\section{INTRODUCTION}

Rebuilt in 857 AD, the East Main Hall of Foguang Temple is the highest ranking wooden architecture to survive from the Tang Dynasty, with a majority of its wooden components still maintain the original structure and material from its original construction; while many of the clay sculptures, murals and inscriptions retained are remains from the Tang Dynasty as well. Praised as "the top treasure of Chinese ancient architecture" by Mr. Liang Sicheng, the East Main Hall of Foguang Temple is regarded as a rare cultural and architectural gem of China and of the world at large.

Since its rediscovery in 1937, extensive research on the East Main Hall of Foguang Temple has been conducted, including investigations, surveys, and preservation research studies, which has produced large amount of documentation and research materials. Since the introduction and utilization of digital documentation methods in the surveys and studies of the East Main Hall in 2005, accumulated digital documentation materials provided a solid foundation not only for further preservation related research studies, but are also important sources of content for heritage interpretation and presentation. However, while scholars focus on preservation related research, few attentions are given to the interpretation and representation of the East Main Hall of Foguang Temple, especially to the public audiences.

Based on continued digital documentation and study of the East Main Hall of Foguang Temple by Tsinghua University and Beijing Guowenyan Cultural Heritage Conservation Center over the past 16 years, a systematic attempt to leverage digital documentation and acquired research results as content and tool for heritage interpretation and presentation is conducted, with the aim of developing emotional connections between the public and the East Main Hall of Foguang Temple.

\section{FOUNDATION: CONTINUED DIGITAL DOCUMENTATION AND RESEARCH}

\subsection{Digital Documentation Projects of the East Main Hall of Foguang Temple}

From 2005 to 2011, the Cultural Heritage Conservation Team of Tsinghua University conducted a comprehensive on-site digital survey and documentation project on the large wooden structure of the East Main Hall. Through the utilization of leading 3D laser scanning equipment at that time, the project team obtained 3D information and carried out special research such as measurement research and disease damage analysis based on 3D point could modelling. The project achieved remarkable research results; the millimeter-scale survey assisted researchers in distinguishing the "present status mapping" derived through digital data apart from the "ideal layout" derived through manual measurements and literature research. The project result "Survey and Research on the Main Hall of Fo Kuang Ssu" was published by Cultural Relics Publishing House in April 2011. 


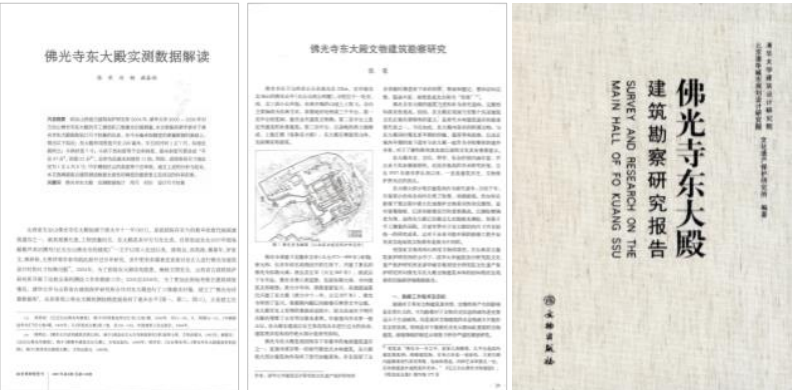

Figure 1. Phase 1 survey research results published

In 2015, Beijing Guowenyan Cultural Heritage Conservation Center Co., Ltd. and the Cultural Heritage Conservation Team of Tsinghua University carried out the second phase of the comprehensive digital survey, in which the survey and research objects are extended to the colored statues, murals, inscriptions and colored paintings in and around the East Main Hall; these cultural relics can better reflect the traces of history of the East Main Hall from its completion to the present. Through careful analysis and logical deduction, they could reveal the development and changes of the East Main Hall in various historical periods. This project was composed of four parts: digitization, survey, monitoring, and information collection and management.
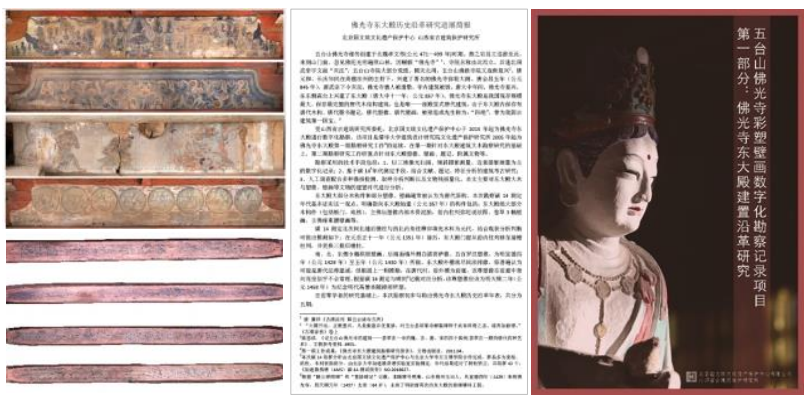

Figure 2. Phase 2 survey and research work

The two phases of digital survey and documentation achieved rich and important research results through in-depth analysis on the refined survey results and massive digital data collected, including breakthrough researches on the modules system of the East Main Hall, the figure identity of the statues, the figure and content of colored paintings, the time of repainting of the murals and the statues, the evolution of the construction and transformation of the East Main Hall, and the spatial relationship and changing trends between the architecture and the statues inside...etc. These research results are important source of content for the interpretation and presentation of the East Main Hall to the public.

\subsection{Online Database Platforms}

The project team built two database platforms for the data collected in the two phases of digital survey and documentation: "Digital Information Platform of the East Main Hall of Foguang Temple" and "Monitoring System of World Heritage Foguang Temple of Mt.Wutai".

The first platform "Digital Information Management Platform of the East Main Hall of Foguang Temple" is an advanced 3D engine digital platform upgraded from the previous GIS-based large wooden structure information database (CHIS) system, with the massive digitized information and results newly retrieved from the project. The new platform incorporates not only survey results, but also testing and experimental analysis results, empowering the platform to systematically manage all the digital data based research and analysis of the East Main Hall.

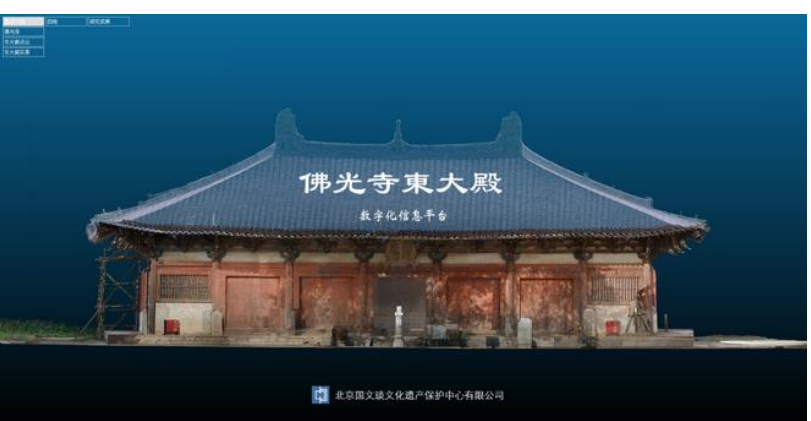

Figure 3. Digital Information Management Platform of the East Main Hall of Foguang Temple, developed by Beijing Guowenyan Cultural Heritage Conservation Center

The second platform "Monitoring System of World Heritage Foguang Temple of Mt.Wutai", is an online database system that aggregates the real-time monitoring data retrieved from the ongoing monitoring project; the system has the function of online viewing and analysis via the Internet at any time, and can set thresholds to alarm when significant changes of architecture components and the environment are sensed.

\subsection{Digital Survey and Interpretation}

The process of digital survey research itself is the process of analyzing, understanding, and interpreting the heritage value. In view of cultural heritage presentation and interpretation, digital survey results can be used as important source of material. With the help of online interactive display functions, developing a digital information platform that not only manages all the data, showcases conservation research results, but also delivers the value of the East Main Hall to the public in an explorational and dialogical way is the aim of the digital survey project in the next phase.

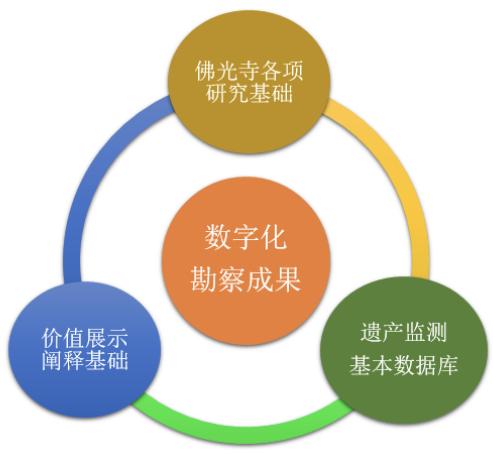

Figure 4. Project goal of future digital survey project

\section{TRANSLATION OF DIGITAL SURVEY DATA INTO INTERPRETATION CONTENT}

\subsection{First Approach: Development of On-site Digital Display System-—Direct Utilization of Digital Data}

The current on-site display infrastructure of Foguang Temple is surprisingly insufficient; tourists without professional background usually find it difficult to understand the outstanding value and historical status of Foguang Temple on-site.To improve this situation, the project team proposed an on-site digital display and exhibition plan and developed a portable 
digital navigation system that incorporates the digital data retrieved from the survey project.

The first part of the plan is to design an on-site visual signage system that includes directional signs, explanatory signs, functional guide signs, etc.

The second part is to develop a portable digital navigation system that works on a local area network and is embedded into an iPad or a portable tablet. The system incorporates processed image and 3D model information (digital survey retrieved data) with realworld environment in a built-in system, highlighting the captivating features, facts, and details of the East Main Hall; with the help of the portable system, visitors could learn more about the historical background, and facts behind the structure, stories about how the temple is rediscovered, related figures and other facts and stories about the Foguang Temple, thereby guiding tourists to develop a better understanding of the value of the precious cultural relics. Furthermore, the portable digital navigation system works together with the visual signage system, by scanning QR codes printed on different visual signs, visitors could have access to extended information, and interactive gaming functions, enhancing the on-site visit experience.

The third part is to convert three empty non-heritage buildings into a series of exhibition spaces, hosting a comprehensive onsite exhibition that utilizes digital display technology. By processing digital survey data into presentable formats (including high-definition images and interactive 3D models), and translating conservation related research results into a storyline, the exhibition could help visitors construct a systematic understanding of the value of the Foguang Temple. Moreover, the exhibition could incorporate the latest survey, monitoring and research processes, presenting the work and perspective of conservation professionals, helping visitors understand cultural heritage conservation from a different perspective.

The three-part on-site presentation strategy is still in the drafting phase; the project team has developed a trial version of the portable digital navigation system named "Meet with the masters in Foguang Temple" which was installed in portable tablets and tested on-site by visitors for free.

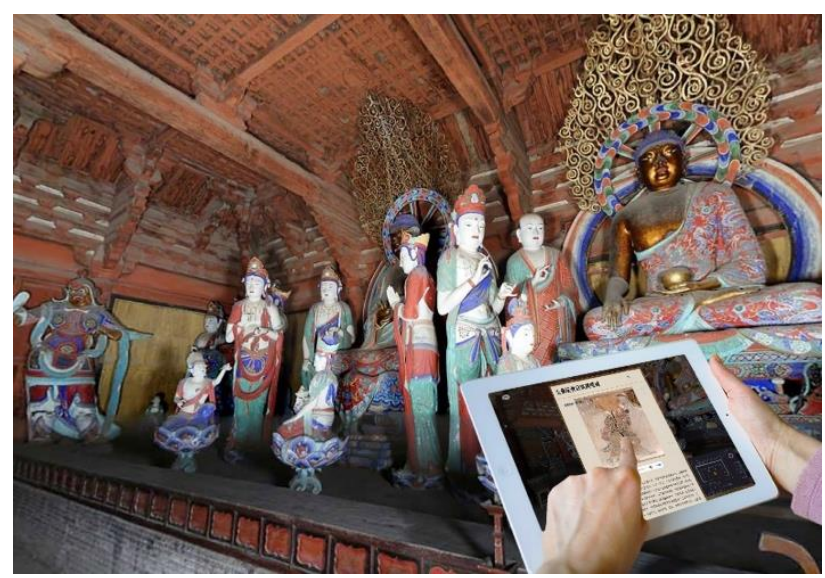

Figure 5. Portable digital navigation system in use on-site

The trial version's main functions are information highlight and tour guidance. Information highlight consists of five functions: comprehensive background introduction, extended information on key features, enlarged introduction of on-site content, comparison of historical information, and knowledge point interactive games. Visitors can enter panoramic videos of different historical scenic spots from the initial navigation map interface, select the information tags attached to the panoramic videos, which synchronizes with the real scene, and choose the information highlight points of their interest to see extended information that they cannot get onsite. The extended information attached to the system includes not only professional knowledge derived and translated from academic research, such as Dougong Design, types of Colored Painting, etc., but also includes short stories such as the rediscovery of Foguang Temple (with Mr. Liang Sicheng and Ms. Lin Huiyin as the narrators), and interactive games such as "search for inscriptions", making the system more appealing to the visitors.

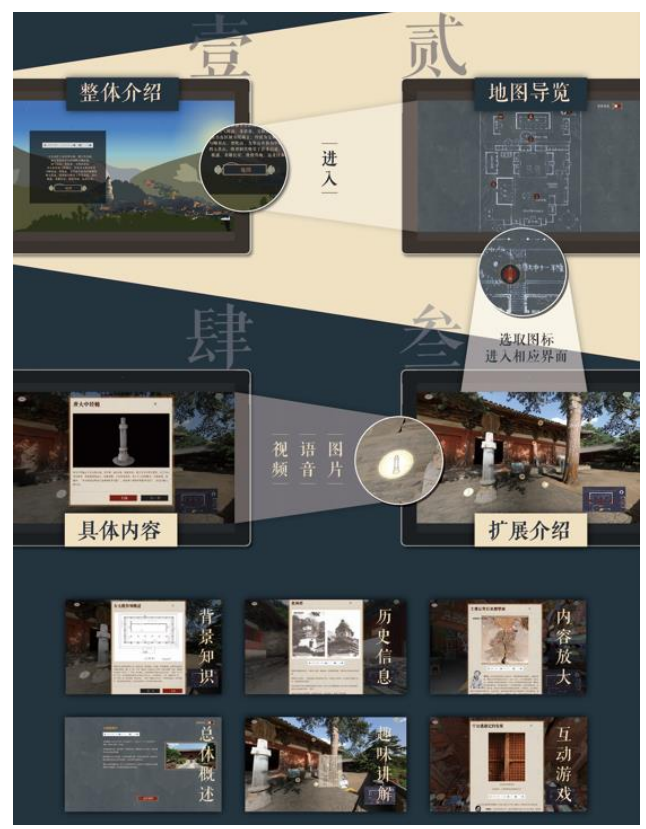

Figure 6. "Meet with the masters in Foguang Temple" Portable digital navigation system (trial version), developed by Beijing

Guowenyan Cultural Heritage Conservation Center

The trial version of the portable digital navigation system was installed in portable tablets and tested on-site by visitors for free in 2017. The project team deigned a user-experience questionnaires for the trial system; visitors could use the system for free in exchange of leaving their experience comments on the questionnaires. Overall, $70 \%$ of users think that the system greatly enhanced their on-site experience, with the rest $30 \%$ think that the system slightly enhanced their on-site experience.

In general, most trial version users find the system in some way enhanced their experience, but more attention to the upgrade of system stability and fluency and improvement of interactive experience should be paid. The project team plans to incorporate augmented reality technology to link processed image and 3D model information (digital survey retrieved data) with real-world environment captured by camera on the device in the future, thereby enhancing the on-site experience in a more interactive way.

\subsection{Second Approach: Planning of a large-scale Interactive Museum Exhibition-C Content Translation of Digital Data}

In view of its special historical status, introductions about Foguang Temple frequently appear in books, magazines, exhibitions, and documentaries related to ancient architecture. The content mostly focuses on brief introduction of the outstanding value of Foguang Temple and its discovery process, 
with few contents extend to the relationship between the discovery of Foguang Temple and the development of Chinese architectural history as a discipline. Specific presentations about the cultural relics of Foguang Temple are mostly found in professional publications such as essays and writings. The lack of popular interpretation materials for ordinary audiences and tourists makes it difficult for non-professional enthusiasts to have an in-depth understanding of the specific content and extended background of the cultural relics of Foguang Temple.

Shanxi Province is not only the home of Foguang Temple, but is also the home of over 150 pre-Yuan architecture, which accounts for over $80 \%$ of China's pre Yuan architecture heritage. As one of the most precious ancient architecture heritage in China, the East Main Hall of Foguang Temple is undoubtably a star in Shanxi's ancient architecture culture.

In 2019, the project team proposed a museum exhibition plan to introduce Foguang Temple as a new cultural brand of Shanxi Province. Preparation for the exhibition proposal involves three phases: exhibition research, exhibition outline, and exhibition text.

In the first phase, exhibition research mainly involves in-depth study and research of digital survey and documentation results and other conservation related research of the East Main Hall. The exhibition is aimed for audiences of non-professional background, so balance between telling stories from an expert's perspective and telling stories from the audiences' perspective need to be considered. Thus, content selection and means of display need to be taken into consideration at the same time of research result translation.

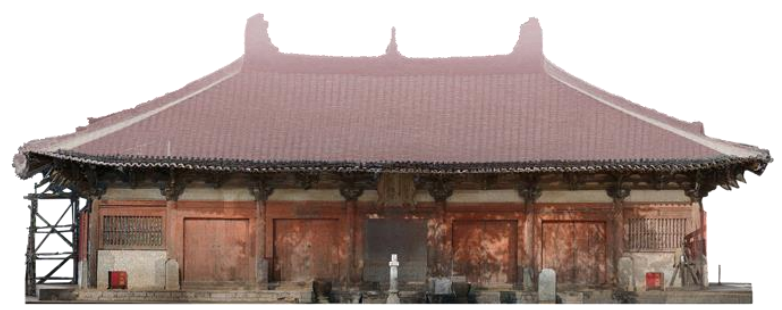

Figure 7. Exhibition image- front elevation of the East Main Hall- point cloud model image processed

In the second and third phase, Storylines and exhibition clues were picked out among the massive documentation data and research results to form a complete exhibition outline, and research-related content are translated into exhibition content in the writing of exhibition texts.

Based on the previous and ongoing digital survey and documentation projects, the project team picked and summarized exhibition content into five modules that represent "the narrative module", "the knowledge module", "the fun module", "the experience module", and "the clue module"; These modules can be connected in series or disassembled in different ways according to different venues and display requirements.

- "The narrative module" focuses on the story of discovering Foguang Temple in 1930s, with related stories of the social background and famous scholars related to this legendary discovery. In this module, historical photos and archives are included.

- "The knowledge module" focuses on the construction history of Foguang Temple, through "decrypting" the codes behind ancient architecture of Tang Dynasty; the construction of the East Main Hall includes a group of hidden numbers; these numbers together constitute the construction logic of the Buddhist temples in the Tang Dynasty and are the password of the East Main Hall. These "numbers" are derived from the survey and documentation projects and research results, such as statue placement, pilgrims' sight lines, "Cai Fen" system, roof truss slope, all of which were found to be considered comprehensively during the design process of the East Main Hall according to the newest studies. The design thinking behind these numbers constitutes the construction logic of the East Main Hall, which would be translated into a series of "number" related fact points that uses animation, digital models, physical models, and interactive games (research data and models processed into presentable formats) to help audiences understand the construction wisdom of Tang Dynasty.

- "The fun module" focuses on the statues, murals, colored paintings, and inscriptions of the East Main Hall; by selecting and translating information highlights found in recent research that are fun and attractive to audiences, such as the identity of the mysterious owner, the mismatching colored-paintings, the monkey locked behind the statue, etc. In this module, historical photos, archives, animation, and interactive games are adopted.

- "The experience module" is a dynamic immersive visual show that combines spatial model, holographic projection display, and real-scene performance.

- "The clue module" is the main storyline of the exhibition, with a little bat exploring the Foguang Temple, guiding audiences through the themes and stories to learn what lies behind the thousand years of history of the Foguang Temple.

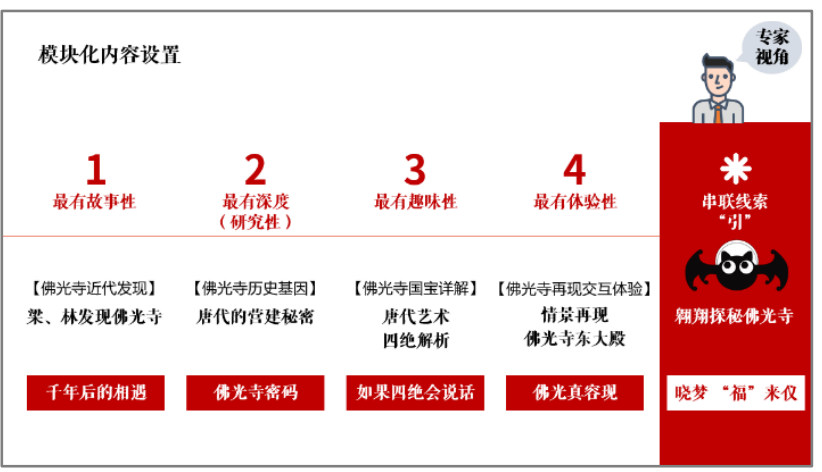

Figure 8. Five modules of exhibition content

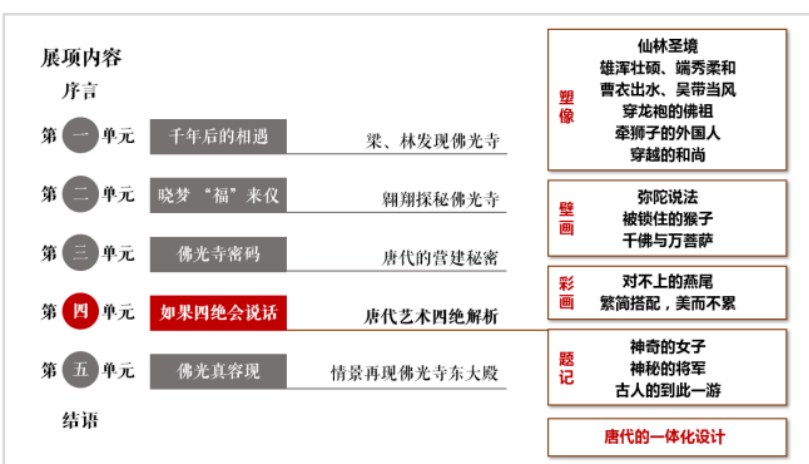

Figure 9. List of content headings of "the fun module"

The first draft of the exhibition proposal was completed in 2019; modifications and revisions on the translation of research results into exhibition contents are still in progress. 


\subsection{Third Approach: Mass Dissemination-Videos on Social Media- - Mass Communication of Digital Data}

The above mentioned two approaches are targeted at either onsite tourists or museum visitors, while the research outcome can reach out to a wider scope of public on the Internet. The idea of the Internet users being passive consumers has been eclipsed by Web 2.0 tools such as social media, which provided opportunities for interactive communication to the previous one-way communication online environments (Cann, Dimitriou, \&Hooley, 2011; Kaplan \& Haenlein, 2010).

With these features, social media has also brought changes to education. Encouraging participation and engagement, social media share principles in line with modern educational theories by facilitating rapid knowledge dissemination and collaboration. As one of these theories, connected learning is defined as a type of learning advocates for "socially embedded, interest-driven" (Ito et al. 2013:4). Ito et al. stressed the importance of new media (including social media) in facilitating connected learning by:

- $\quad$ Fostering engagement and self-expression;

- Increasing accessibility to knowledge and learning experiences;

- $\quad$ Expanding social supports for interests; and

- Expanding diversity and building capacity.

With the prosperity of social media in China, heritage institutions are showing increasing interests in online education and knowledge mobilization ${ }^{1}$. Especially, lockdown and isolation during the COVID-19 epidemic have speeded up the process of opening up access to cultural heritage related data and information. Therefore, the project team decided to further translate and deliver the research work to social media users in 2020.

Under mass communication context, there is a bias of sense experience so that we tend to experience the world in visual imagery (Hartley, 1992) or an involving and participant way (McQuails, 2010). Regarding this, it became obvious that the previous research and documentation work need to be reorganized and recreated in a new visualized form if they were to be disseminated on social media. Therefore, the animation series "Foguang Rediscoveries" was made, the scripts of which are derived from the previous two translation approaches. The animation combines image form of digital documentation and 3D visualization work as well as some stop motion animation shoot on the physical models of the temple. Physical cartoon characters were also designed and made as the cast in stop motion.

By translating the documentation and academic work into stories, the project team hope to provide access of heritage related knowledge to more people. As a trial of this kind, the animation series committed to explore the use of social media not only for heritage research dissemination, but also for connected learning of heritage-related knowledge on social media. Furtherly, another key purpose is to build a dialogical model of heritage on social media. Given to the professionalization of cultural heritage, Harrison (2013) suggests more dialogical models of heritage conservation in which "heritage is seen as emerging from the relationship between people, objects, places and practices" (Harrison, 2013:223). The chains of connectivity between the

\footnotetext{
${ }^{1}$ the connection between academic research or creative works and organizations, people, and government to improve programming and inform policy change.
}

material heritage and the people related to it can contribute to the heritage values.

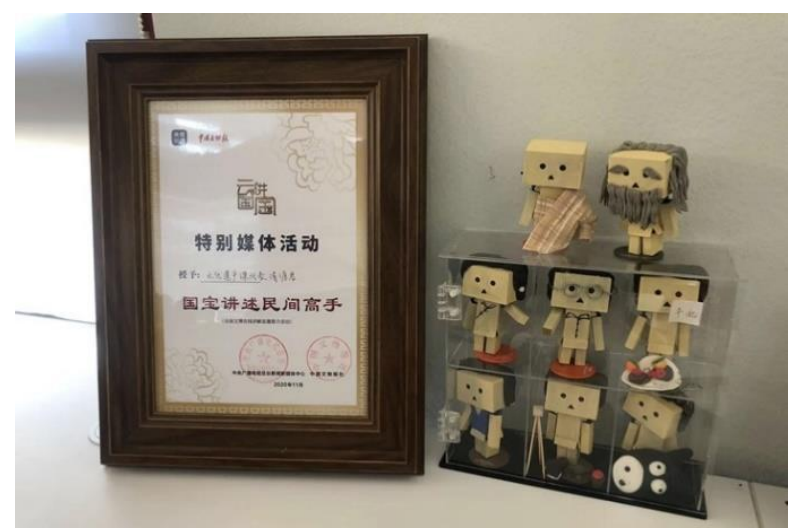

Figure 10. The cartoon characters used in the animation series

Although the episodes share the same artistic style of casts, character voice, and physical models as stage set, their outlines and narratives are organized in different ways to serve various themes. The first episode focuses on representing how the investigation group rediscovered the Foguang Temple, therefore a linear narrative is used to make audiences feel as if they were on the spot with the protagonists. In the second episode, on the contrary, the story is set using Point of View (POV) and imitates a popular variety show called Crime Scene. Scholar characters from different times were gathered; they acted as detectives and collected evidences respectively to find out the whole picture of historical restoration of the East Main Hall. As episode 2 shows academic history across the century and engaging people from different times, POV allows main characters to state their findings from their own standpoints.

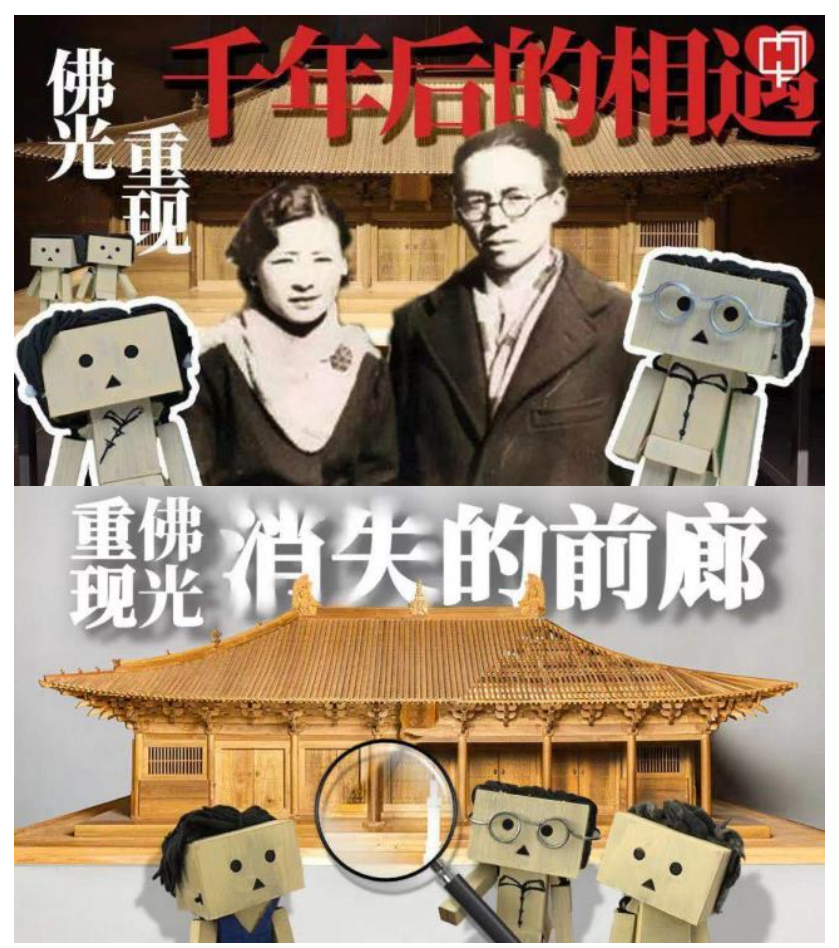

Figure 11. Covers of the first two episodes of animation series: Foguang Rediscoveries 
The first episode was uploaded on social media platforms on July 9, 2020, the same date on which the news of finding the Foguang Temple was reported in the press in 1937. The second episode was uploaded on November 10, 2020, the date that the East Main Hall was built ${ }^{2} 1163$ years ago. At these time point, social media users' wiliness to view and repost the video might be increased than usual days.

As shown in table 12, the two episodes have been watched 17,915 and 90,163 times respectively until May 2021. The most viewed social media platform of the animation is Weibo, mainly because the videos were reposted by some Social Media Influencers. On Bilibili platform, the animation gained highest number of user interactions. According to the data, dissemination performances are closely related to the features and preferences of different platforms. Comparing to previous posts of Foguang Temple that are mainly in texts and pictures, videos have significantly increased the number of views and comments and expanded dissemination scale.

Table 12. Dissemination statistics (Data collected on May7, 2021)

\begin{tabular}{|c|c|c|c|c|}
\hline $\begin{array}{c}\text { Social } \\
\text { Media } \\
\text { Platforms }\end{array}$ & Metrics & $\begin{array}{c}\text { Episode } \\
1\end{array}$ & $\begin{array}{c}\text { Episode } \\
2\end{array}$ & Sum \\
\hline \multirow{2}{*}{$\begin{array}{l}\text { Tencent } \\
\text { 企我号 }\end{array}$} & view & 2,542 & 59,000 & 61,542 \\
\hline & comment & 0 & 2 & 2 \\
\hline \multirow{4}{*}{$\begin{array}{l}\text { Weibo } \\
\text { 微博 }\end{array}$} & view & 4,886 & 27,000 & 31,886 \\
\hline & comment & 2 & 5 & 7 \\
\hline & Thumbs up & 17 & 49 & 66 \\
\hline & Repost & 12 & 98 & 110 \\
\hline \multirow{2}{*}{$\begin{array}{l}\text { Zhihu } \\
\text { 知乎 }\end{array}$} & view & 962 & 348 & 1,310 \\
\hline & Thumbs up & 5 & 2 & 7 \\
\hline \multirow[t]{5}{*}{ Bilibili } & views & 1,504 & 1,109 & 2,613 \\
\hline & comments & 11 & 25 & 36 \\
\hline & Thumbs up & 59 & 99 & 158 \\
\hline & $\begin{array}{l}\text { add to } \\
\text { collection }\end{array}$ & 43 & 59 & 102 \\
\hline & $\begin{array}{l}\text { Repost and } \\
\text { share }\end{array}$ & 41 & 18 & 59 \\
\hline \multirow{2}{*}{$\begin{array}{l}\text { Baidu } \\
\text { 百家号 }\end{array}$} & view & 1,096 & 24 & 1,120 \\
\hline & Thumbs up & 6 & & 6 \\
\hline $\begin{array}{l}\text { Wechat } \\
\text { 微信公众 } \\
\text { 号 }\end{array}$ & view & 6925 & 2682 & 9,607 \\
\hline Total & & 17,915 & 90,163 & 108,078 \\
\hline
\end{tabular}

Many comments were received under the animation. Most commentators said they get more knowledge about history and related scholars of the heritage, and planned to take a trip to the place. Two of them thought these videos help to memorize several contents for postgraduate entrance examination. Some professionals even help to add some background information and made academic arguments in comments. In addition, some heritage agendas have also reposted the videos. These reflections imply that social media facilitates the connected learning of heritage by expanding social supports for interests and building capacity for various users. Furtherly, the relationships were built between human actors such as online users, heritage agendas, experts, and non-human actors like the Foguang temple and the subject of architecture. In the connectivity, social and potentially economic values were added to the heritage in this dialogical model.

\subsection{Synergy Effect of Three Approaches}

Although the three approaches mentioned above have different target audiences, the different technical routes adopted in translating data into content achieved a synergy effect in developing interpretation and dissemination strategies.

For instance, research on the transformation of the layout of the East Main Hall were widely studied, with special attention paid to the restorations in Yuan Dynasty that is believed to have led to a significant change in the layout of the East Main Hall. Based on the digital data of the "evidences" of this change retrieved from the survey projects, related studies were translated into an information tag attached to the panoramic videos labelled "did the doors move?" in the portable digital navigation system, which focuses on leading the visitors to find evidences of the change of place of East Main Hall's front doors. In the second approach, the same set of data and research information were expanded into a sub-sector of the exhibition themed "disappearance of the front porch", explaining how the socio-religious development of Yuan Dynasty had led to the restoration of the spatial layout of the East Main Hall (Table 14). The same theme was then adopted in the third approach, where episode 2 of the animation series used "disappearance of the front porch" as the storyline in the script, with some screen shoots taken from the display system being edited into the video.

\begin{tabular}{|c|c|c|c|}
\hline \multicolumn{3}{|c|}{ 展示内容 } & 可选择的展示方式/技术 \\
\hline \multicolumn{4}{|c|}{ 第二单元：佛光寺密码一一唐代的营建秘密 } \\
\hline \multicolumn{2}{|c|}{ 五台山的耧密 } & 佛光寺、五台山、 & - 图文板 \\
\hline \multirow{6}{*}{$\begin{array}{l}\text { 侓光寺密码 } \\
\text { 佛光类始 } \\
\text { 建空间解析 }\end{array}$} & 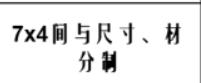 & 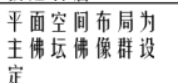 & \multirow{6}{*}{ 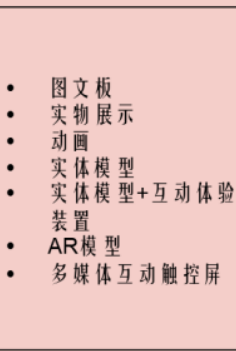 } \\
\hline & 18尺 & $\begin{array}{l}\text { 佛教塑隐尺度的 } \\
\text { 五史规律 }\end{array}$ & \\
\hline & $\begin{array}{c}31^{\circ} \text { 与14.7尺, } 46^{\circ} \\
\text { 与16.8尺 }\end{array}$ & $\begin{array}{l}\text { 剖面设计考虑视 } \\
\text { 线与塔设的关系 }\end{array}$ & \\
\hline & 21毫米,7寸与7朝作 & $\begin{array}{l}\text { 东大䁚的材份和 } \\
\text { 斗栱制度 }\end{array}$ & \\
\hline & $\begin{array}{l}2.5 \text { 分 }^{\circ}{ }^{3.5} . \text { 分 }^{\circ} 、 \\
.5\end{array}$ & $\begin{array}{l}\text { 使立面曲线优美 } \\
\text { 数和的等差 }\end{array}$ & \\
\hline & $24.08^{\circ}$ 与11倍 & 最后一颗龙珠 & \\
\hline \multirow{2}{*}{\multicolumn{2}{|c|}{ 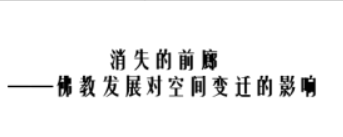 }} & 右绕式与叫看式 & \multirow[b]{2}{*}{ 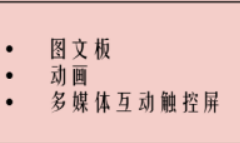 } \\
\hline & & $\begin{array}{l}\text { 佛光寺历代修籍 } \\
\text { 活动以及其与礼 } \\
\text { 沸功能仪轨变化 } \\
\text { 的关系 }\end{array}$ & \\
\hline
\end{tabular}

Figure 13. Parts of exhibition outline related to "Disappearance of the Front Porch"

In the three approaches, although academic information is translated and processed according to various channels of dissemination and different heritage audiences and consumers (Fig.15), it is still clear that the results of previous approaches could substantially complement to the later dissemination strategies.

\footnotetext{
2 According to the text on Jingchuang (sutra pillar) and lunar calendar of Tang dynasty, the temple was built on November $10, \mathrm{AD} 857$
} 


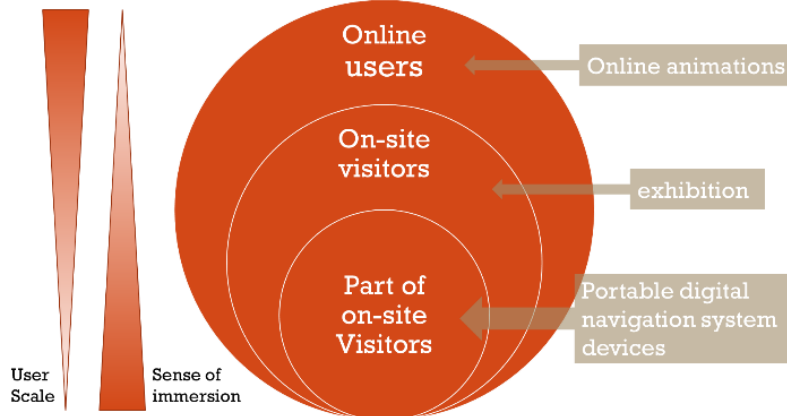

Figure 14. Comparison of different interpretation and dissemination approaches.

\subsection{Application Difficulties}

There are inevitable application difficulties of content translation of academic work for interpretation and representation purposes, especially when the content is intended for a wider audience. In the above mentioned three approaches tested by the project team, the most difficult approach is the third approach, when content translation reached out to a wider scope of public on the Internet.

In his book, MaQuails concluded types of media bias (McQuails 2010:172) in mass communication. Some of these media bias can also be reflected in the dissemination of videos, including bias form and representation as well as message content. In this case, firstly, the contents derived from academic work were selected and adapted to make it easier to be understood and be reposted by social media users. However, it might lead to simplification and even loss of some research and documentation message. Secondly, messages were strongly coded in the 3D visualization, the models, and even the photos taken from Foguang temple. Therefore, the bias of form and representation are inevitable after the coded messages were being disseminated online and uncoded by social media users.

The outcome of dissemination of animations tends to be influenced by social media platform algorithms. Further dissemination of the videos will be impacted by metrics including views, retention of audience throughout the duration of the videos, average watching time, and so on. As a result, videos in relatively short time length $(<5 \mathrm{~min})$ with low information density and simple content. However, video aiming at delivering knowledge often failed to compress its content into a small volume. In the animation series of Foguang Temple, we looked to keep a balance between ensuring the content integrated and accurate and keeping the time length relatively short. Nevertheless, the data still underperformed in audience retention (see table 13).

Table 15. Views, retention of audience, and average watching time of the animation on Tencent. (Data collected on May7, 2021)

\begin{tabular}{|l|l|l|}
\hline & Episode 1 & Episode 2 \\
\hline Views & 2628 & 59240 \\
\hline Retention of audience & $11.4 \%$ & $4 \%$ \\
\hline $\begin{array}{l}\text { Average watching } \\
\text { time (min) }\end{array}$ & 0.5 & 0.3 \\
\hline Time length & $03: 49$ & $07: 11$ \\
\hline
\end{tabular}

\section{CONCLUSION}

The past twentieth century has seen the professionalisation and bureaucratisation of heritage practice, with laypersons and communities being increasingly locked out of involvement heritage conservation (Carman 2005; Smith and Waterton 2009b).
With the rise of new technologies in heritage documentation, visualization and dissemination, a wider scale of public will be enabled to engage in heritage process.

In the case of reinterpretation and representation of the Foguang Temple, digital documentation and study of the East Main Hall were translated in three approaches: on-site digital display system, the planning of a large-scale interactive museum exhibition, and animation series on air at multiple social media platforms. The first two approaches serve visitors on-site with immersive and interactive experience. The third approach focuses on social media users and aim to arise discussion about the heritage. All three of these methods facilitated connected learning of cultural heritage and build up connectivity between people and heritage.

Seeing the application difficulties, the potential media bias in the dissemination need to be considered. It is also worth thinking how to achieve a balance between the integrity and accuracy of content and the overall arrangement (time length, information density etc.) preferred by social media platform algorithm. Further research and surveys might be carried out to explore the audiences' perceptions of the mentioned interpretations. In the future, more new approaches of translating academic work should be explored and adopted in cultural heritage dissemination and education.

\section{REFERENCES}

Rong.Zhang., Xian.Lei., Qi.Wang., Ning.Lv., Shuai.Wang., (2018) A Study on Contruction Histroy of Main Hall of Foguangsi(Fo Kuang Ssu). Architectural History, 41(1), pp. 3152 .

Yumin.Li., Rong.Zhang.(2019). Monitoring of Deformation of the Foguang Temple's East Main Hall Under the Concept of Preventive Conservation. The International Archives of the Photogrammetry, Remote Sensing and Spatial Information Sciences, Volume XLII-2/W15, 2019.

McQuail, D. (2010). Mass communication theory. Sage publications.

Hartley, J. (1992) The Politics of Pictures. London: Routledge.

Joel Taylor \& Laura Kate Gibson (2017) Digitisation, digital interaction and social media: embedded barriers to democratic heritage, International Journal of Heritage Studies, 23:5, 408-420, DOI: $10.1080 / 13527258.2016 .1171245$

Colleen Morgan (2014) Archaeology and the Moving Image, Public Archaeology, 13:4, 323-344, DOI: $10.1179 / 1465518715 Z .00000000077$

Cooper, A. (2014). The use of online strategies and social media for research dissemination in education. Education Policy Analysis Archives, 22(88).

Smith, L. (2006). Uses of heritage. Routledge.

Harrison, R. (2012). Heritage: critical approaches. Routledge.

Anderson, P. (2007). What is Web 2.0?: ideas, technologies and implications for education (Vol. 1, No. 1, pp. 1-64). Bristol: JISC. 
Bennet, A., Bennet, D., Fafard, K., Fonda, M., Lomond, T., Messier, L., \& Vaugeois, N. (2007). Knowledge mobilization in the social sciences and humanities. Frost, WV: Mqi Press.

Scolari, C. A. (2012). Media ecology: Exploring the metaphor to expand the theory. Communication theory, 22 (2), 204-225.

Strate, L. (2004). Media ecology. Communication Research Trends, 23(2), 1-48.

Fuller, M., \& Malina, R. F. (2005). Media ecologies: Materialist energies in art and technoculture. MIT press.

Taffel, S. (2019). Digital media ecologies: Entanglements of content, code and hardware. Bloomsbury Publishing USA.

Ito, Mizuko, Gutiérrez, Kris, Livingstone, Sonia, Penuel, Bill, Rhodes, Jean, Salen, Katie, Schor, Juliet, Sefton-Green, Julian and Watkins, S. Craig (2013) Connected learning: an agenda for research and design. Digital Media and Learning Research Hub, Irvine, CA, USA. ISBN 9780988725508 